\title{
Linfocitose extrema associada à leucemia linfoblástica aguda (LLA) de células T em um cão jovem: relato de caso*
}

\section{Extreme lymphocytosis associated with acute T-cell lymphoblastic leukemia (ALL) in a young dog: case report}

\author{
Gabriele Barros Mothé, ${ }^{* *}$ Paloma Helena Sanches da Silva, ${ }^{* * *}$ Sabrina Destri Emmerick Campos, ${ }^{* * *}$ Victor Nowosh, ${ }^{* * * *}$ \\ Nayro Xavier de Alencar****
}

\section{Resumo}

A leucemia linfoblástica aguda (LLA) é uma enfermidade de origem linfóide e consiste na proliferação de células neoplásicas na medula óssea. O objetivo desse trabalho é relatar o caso de um cão macho, sem raça definida, de apenas um ano de idade, atendido no Hospital Universitário de Medicina Veterinária Prof. Firmino Mársico Filho (HUVET) da Universidade Federal Fluminense (UFF) com queixa principal de inapetência e diarreia há três dias e que foi diagnosticado com essa neoplasia por meio da sintomatologia clínica, resultados do hemograma e do mielograma. O paciente apresentava valores exacerbados de linfócitos (553.094 células/ $\mu \mathrm{L}$ ), além de anemia, trombocitopenia, hipoalbuminemia e elevação da atividade das enzimas fosfatase alcalina e ALT. Foram observadas manchas de Gümprecht, linfócitos atípicos apresentando anisocitose, anisocariose, intensa basofilia citoplasmática e monócitos ativados. O mielograma apresentou também um aumento de linfócitos e contagem de linfoblastos superior a $30 \%$ na medula, confirmando o diagnóstico de leucemia linfoblástica aguda. Ademais, posteriormente, foi realizado exame de Reação em Cadeia de Polimerase (PCR) para rearranjos de receptores de antígenos e foi detectado clonalidade para linfócitos T. O animal foi submetido à quimioterapia (protocolo com ciclofosfamida, vincristina e prednisona) mas não resistiu à gravidade do quadro, vindo a óbito após a primeira sessão, pouco tempo após o diagnóstico.

Palavras-chave: linfócitos atípicos, linfócitos T, mielograma, PCR para rearranjos de receptores de antígenos.

\begin{abstract}
Acute lymphoblastic leukemia (LLA) is a disease with a lymphoid origin and consists of the proliferation of neoplastic cells in the bone marrow. The aim of this study was to report the case of only one year old mixed breed male dog, attended at the University Hospital of Veterinary Medicine Prof. Firmino Mársico Filho (HUVET) from Universidade Federal Fluminense (UFF), with major complaint of inappetence and diarrhea three days ago and which was diagnosed with this neoplasm through clinical symptoms, complete blood count and myelogram results. The patient had increased values of lymphocytes $(553,094 \mathrm{cells} / \mu \mathrm{L})$, in addition to anemia, thrombocytopenia, hypoalbuminemia and elevated alkaline phosphatase and ALT activities. Gümprecht shadows, atypical lymphocytes presenting anisocytosis, anisocariosis, and severe cytoplasmic basophilia and activated monocytes were observed. Myelogram also showed an increase in lymphocytes and a lymphoblastic count greater than $30 \%$ in the marrow, confirming the diagnosis of LLA. In addition, polymerase chain reaction (PCR) for antigen receptor rearrangements was performed and clonality for T lymphocytes was detected. The animal underwent chemotherapy (protocol with cyclophosphamide, vincristine and prednisone), but did not withstand the severity of the disease, coming to death after the first session, shorly after diagnosis.
\end{abstract}

Keywords: atypical lymphocytes, myelogram, PCR for antigen receptor rearrangements, T lymphocytes.

\section{Introdução}

A medicina veterinária tem crescido substancialmente, principalmente no que concerne ao atendimento de animais de companhia. O cão foi a primeira espécie a ser domesticada e atualmente ocupa posição de destaque e de grande importância no cotidiano do homem (Moreira et al., 2018; Barboza et al., 2019).

No entanto, apesar da crescente evolução da medicina veterinária, o câncer ainda é uma das principais causas de morte de pequenos animais. Aproximadamente $45 \%$ dos cães

\footnotetext{
${ }^{*}$ Recebido em 9 de junho de 2019 e aceito em 17 de novembro de 2019.

${ }^{* *}$ Faculdade de veterinária, Universidade Federal Fluminense - UFF, Niterói, RJ, Brasil

***Hospital Veterinário, Universidade Federal de Minas Gerais- UFMG, Belo Horizonte, MG, Brasil

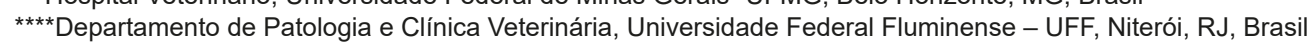

*****Departamento de Patologia, Universidade de São Paulo - USP, São Paulo, SP, Brasil

Autor correspondente: Universidade Federal Fluminense. R. Vital Brasil Filho, 64, Vital Brasil, Niterói, RJ, Brasil. 24230-340. E-mail: gbmothe@usu.edu.br
} 
com mais de 10 anos são vitimados pela doença, sendo as neoplasias cutâneas e subcutâneas as mais comuns (Withrow et al., 2013; Daleck et al., 2016; Barboza et al., 2019).

Os tumores hematopoiéticos são classificados de acordo com suas características clínicas, morfológicas, imunofenotípicas e genéticas em leucemia, linfoma e neoplasia de plasmócitos (Vardiman, 2010). A leucemia consiste, em suma, na proliferação de células neoplásicas na medula óssea que vão, gradativamente, sofrendo uma série de alterações genéticas progressivas e cumulativas, adquirindo características de malignidade (Vail, 2008).

De acordo com os achados clínico-patológicos, a leucemia de origem linfóide pode ser classificada como Leucemia Linfoblástica Aguda (LLA) ou Leucemia Linfocítica Crônica (LLC), sendo esta classificação importante para fins diagnósticos e terapêuticos, além de definir o prognóstico dos animais acometidos (Vail, 2008; Nelson e Couto, 2015).

Acerca da evolução, a LLA tende a ser mais grave devido ao comportamento biológico agressivo, com predomínio de células linfóides imaturas (linfoblastos), na medula óssea e, secundariamente, no sangue, podendo infiltrar órgãos linfóides e outros tecidos; ao passo que a LLC possui curso clínico prolongado com tipo celular predominantemente bem diferenciado (Nelson e Couto, 2015).

O diagnóstico da leucemia pode ser obtido associando os achados clínicos à análise citológica do esfregaço sanguíneo, aspirado de células de linfonodos, órgãos linfóides e pelo mielograma, bem como pela histopatologia e pela imunohistoquímica que tem ainda a finalidade de classificar a linhagem celular das leucemias. Além disso, tem-se adotado também técnicas moleculares (PCR) ou imunofenotipagem por citometria de fluxo para classificar com mais precisão o perfil da leucemia (Adam et al., 2009; Nelson e Couto, 2015).

Frente ao exposto, esse trabalho objetivou relatar o caso de um cão muito jovem apresentando linfocitose exacerbada (553.094 células $/ \mu \mathrm{L}$ ), diagnosticado com Leucemia Linfoblástica Aguda de células T e descrever os achados clínico-laboratoriais dessa doença.

\section{Relato de caso}

Foi atendido no Hospital Universitário de Medicina Veterinária Prof. Firmino Mársico Filho (HUVET) da Universidade Federal Fluminense (UFF) um cão macho, sem raça definida, com um ano de idade, com queixa principal de inapetência e diarreia há três dias. Ao exame físico o animal apresentava apatia, mucosas hipocoradas e hepatomegalia discreta à palpação.

Procedeu-se com exames complementares (hemograma e bioquímica), cujos resultados revelaram as seguintes alterações: anemia normocítica normocrômica, (Hematócrito: 27,0\%) e trombocitopenia $(24.000 / \mu \mathrm{L})$. A leucometria global estava extremamente aumentada ( 570.200 células $/ \mu \mathrm{L})$, com intensa linfocitose (553.094 células/ $\mu \mathrm{L}$ ) e monocitose (11.404 células/ $\mu \mathrm{L})$. Na hematoscopia foram observadas frequentes manchas de Gümprecht, linfócitos imaturos e atípicos apresentando anisocitose, anisocariose e intensa basofilia citoplasmática (Figura 1), além de presença moderada de monócitos ativados.

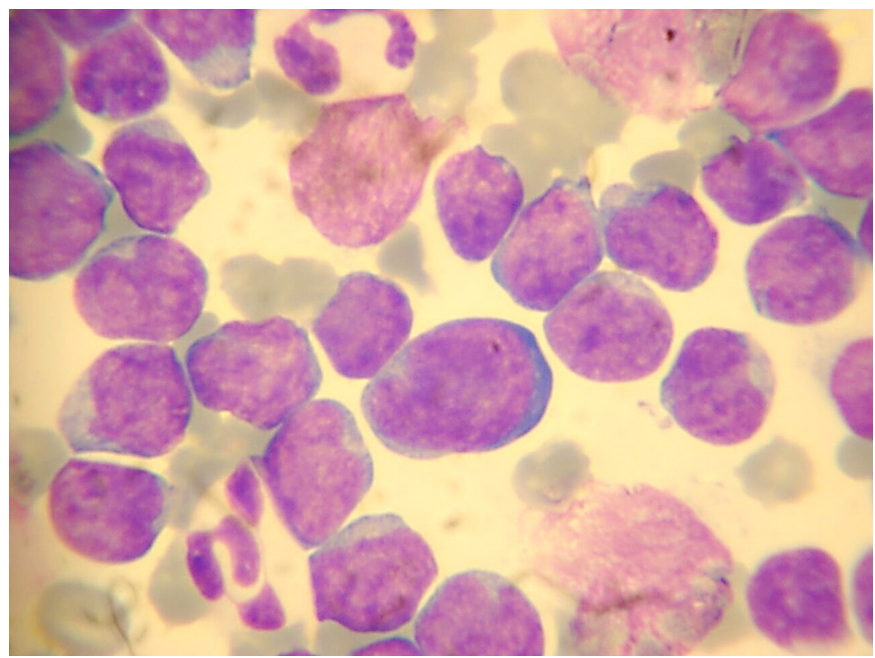

Figura 1: População de linfoblastos observada em esfregaço sanguíneo de paciente com diagnóstico de leucemia linfoblástica aguda, evidenciando moderadas anisocitose e anisocariose, intensa basofilia citoplasmática, múltiplos nucléolos e manchas Gümprecht. Coloração Giemsa, aumento 1000X

Em relação ao resultado da bioquímica sérica, houve uma elevação da atividade das enzimas fosfatase alcalina (447UI/L) e ALT (668UI/L), além de hipoalbuminemia (2,4g/dL). Em função das alterações encontradas no hemograma, o animal foi submetido à punção de medula óssea que revelou um grande número de linfócitos pequenos e mais de $30 \%$ de linfoblastos, os quais apresentavam aproximadamente duas vezes o diâmetro dos eritrócitos, com núcleo central a levemente irregular, e alguns deles com nucléolos evidentes. Os sinais clínicos associados aos resultados do hemograma e mielograma corroboraram para o diagnóstico de LLA.

Para avaliação de clonalidade e classificação fenotípica da leucemia, amostras de sangue e medula óssea foram submetidas à $\mathrm{PCR}$ para rearranjos de receptores de antígenos (PRRA). Para tal, DNA foi extraído de lâminas de sangue e medula óssea com material adequado confirmado à microscopia, utilizando kit comercial (Invisorb ${ }^{\circledR}$ Spin Tissue Mini Kit; Stratec Molecular GMBH, Berlin, Alemanha).

Foram utilizados quatro conjuntos de oligonucleotídeos diferentes: um par para a região $\mathrm{C} \mu$, gene constitutivo correspondendo à porção constante da IgM presente nos linfócitos, servindo para confirmar a presença de DNA linfoide amplificável na amostra; dois pares de oligonucleotídeos tendo a cadeia pesada da imunoglobulina IgH como alvo, denominadas IgH-minor e IgH-major, servindo para detectar rearranjos de linfócitos $\mathrm{B}$; e três oligonucleotídeos em multiplex tendo o receptor TCRy como alvo, para detecção de rearranjos de linfócitos $\mathrm{T}$.

Como controles positivos, foram utilizadas amostras de linfoma sabidamente positivas para cada reação. Como controle negativo, foi utilizada amostra de linfonodo reativo. O protocolo de amplificação utilizado seguiu o descrito por Nowosh et al. (2017). Os produtos da amplificação foram submetidos à eletroforese em gel de agarose $3 \%$ corado com GelRed ${ }^{\circledR}$ (Biotium Inc., Califórnia, EUA). 
Inicialmente, as amostras testadas revelaram positividade para $\mathrm{C} \mu$, confirmando a presença de DNA linfoide amplificável após o processo de extração.

A PCR para IgH-minor evidenciou bandas múltiplas e mal delimitadas, indicando amostra não clonal (Figura 2A), enquanto a PCR para IgH-major não produziu bandas do tamanho esperado (Figura 2B). A reação para TCRy revelou positividade com banda única e delimitada de aproximadamente $90 \mathrm{pb}$, confirmando clonalidade para linfócitos T (Figura 2C). apresentava apenas um ano de idade e era de porte médio, divergindo da média de idade associada à doença.

Os sinais clínicos da doença geralmente são inespecíficos como a apatia e diarreia (Nelson e Couto, 2015), inicialmente relatadas nesse caso, dificultando o diagnóstico precoce. Outras anormalidades como hemorragias e linfadenomegalia podem ocorrer, embora geralmente sejam incomuns nos cães diagnosticados com LLA. Uma vez presente a linfadenopatia nesta doença, a diferenciação do linfoma multicêntrico é

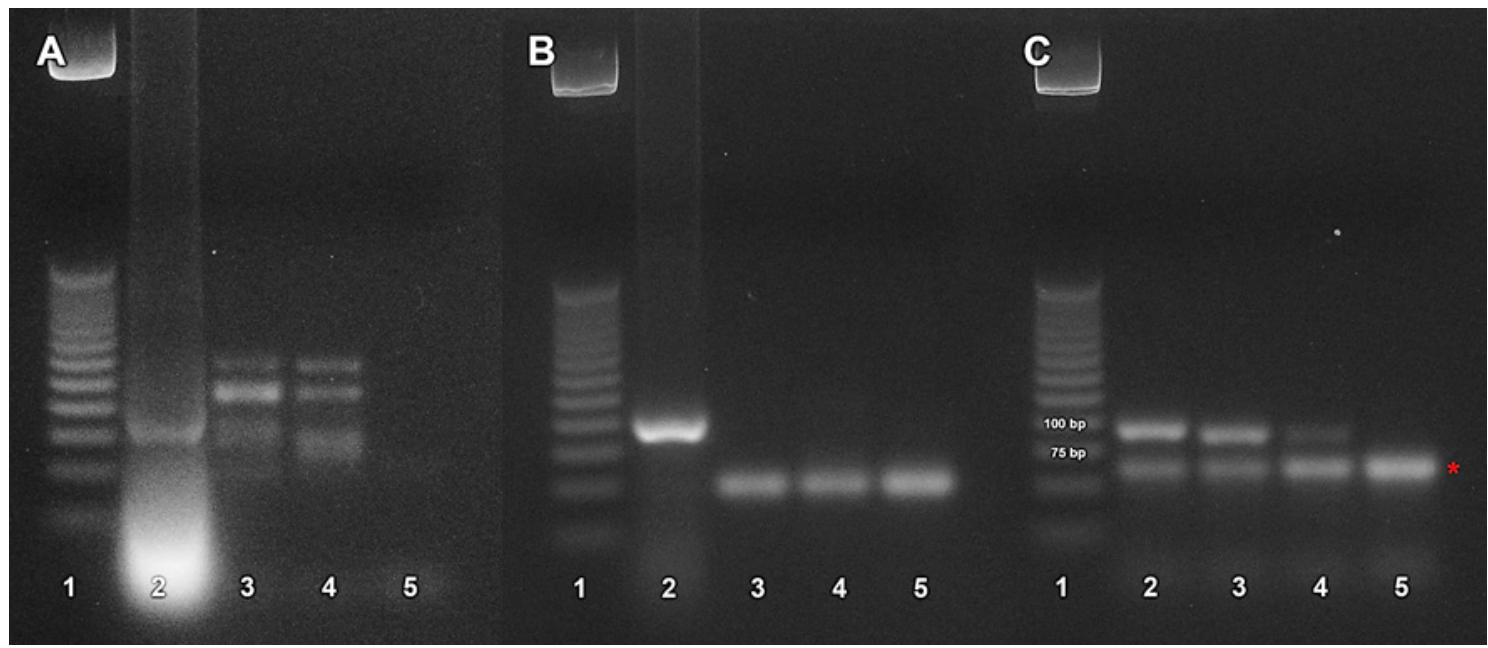

Figura 2: Resultados dos ensaios de clonalidade para amostras de DNA extraídas a partir de sangue e medula óssea de paciente diagnosticado com leucemia linfoblástica aguda. 1 - Marcador de peso molecular 25pb; 2 - Controle positivo; 3 -Amostra de DNA proveniente de sangue; 4 -Amostra de DNA proveniente de medula óssea; 5 - Controle negativo. A-Amplificação para lgH-minor, evidenciando bandas múltiplas e mal delimitadas (3 e 4) diferentes do controle positivo (2); B - Amplificação para IgH-major sem formação de bandas no tamanho esperado (3 e 4); C - Amplificação para TCRY, revelando bandas únicas e bem delimitadas no tamanho esperado (3 e 4), compatíveis com controle positivo (2)

Foi instituída quimioterapia com ciclofosfamida $250 \mathrm{mg} / \mathrm{m}^{2}$, vincristina $0,75 \mathrm{mg} / \mathrm{m}^{2}$ e prednisona $2 \mathrm{mg} / \mathrm{kg}$, a cada $7 \mathrm{dias}$, bem como o tratamento paliativo dos sintomas clínicos. Uma semana após a primeira sessão do tratamento, o paciente veio a óbito. Infelizmente os tutores não autorizaram a realização da necropsia no paciente, impossibilitando assim, a realização de outros exames complementares.

\section{Discussão}

No presente relato, o diagnóstico de LLA baseou-se nos achados do hemograma e mielograma, estando de acordo com Nelson e Couto (2015), segundo os quais a LLA é definida como uma neoplasia maligna, resultante de um distúrbio proliferativo de células linfóides imaturas, denominadas linfoblastos, predominantemente na medula óssea, podendo também estar presente no sangue periférico, e que possui comportamento biológico agressivo e agudo, causando o óbito do animal rapidamente.

Na veterinária, a etiologia ainda não está completamente elucidada, mas tem sido associada a doenças genéticas (Suter et al., 2011). Em uma revisão de 30 casos de cães com essa enfermidade, a idade média foi de 5,5 anos (Matus et al., 1983). Ainda nesse estudo, os autores descreveram que cerca de $27 \%$ dos cães eram da raça pastor alemão e que machos eram mais acometidos. No presente relato, o animal, sem raça definida, dificultada, pois geralmente é encontrada apenas na fase leucêmica do linfoma, sendo possível a diferenciação apenas empregando-se a técnica de imunofenotipagem (Bienzle, 2003). No presente caso, os linfonodos encontravam-se dentro na normalidade à palpação, o que torna a possibilidade de linfoma multicêntrico menos provável.

Anemia, trombocitopenia e leucocitose são algumas das alterações laboratoriais encontradas na LLA. No presente caso, a anemia e a trombocitopenia presentes, podem ser justificadas pela infiltração maciça de linfoblastos na medula óssea, impedindo a hematopoiese normal (mieloftise), resultando na diminuição dos territórios eritróides e megacariocíticos (Nelson e Couto, 2015). Essas alterações quando presentes significam que $50 \%$ ou mais da medula óssea já foi substituída por tecido linfóide (Harvey et al., 1981), reafirmando a gravidade do caso e o prognóstico desfavorável.

No presente relato, o paciente apresentou hepatomegalia à palpação abdominal. Hepato e esplenomegalia são achados comuns em pacientes com LLA e são causados pela infiltração de células neoplásicas nesses órgãos, o que também justifica o aumento das enzimas hepáticas (FA e ALT) e hipoalbuminemia encontradas nesse paciente.

Em relação às anormalidades hematológicas encontradas em cães com LLA, a contagem leucocitária pode apresentar uma variação de 4.000 células/ $\mu \mathrm{L}$ a um valor superior a 
100.000 células/ $\mu \mathrm{L}$ (Couto, 1985). Nesse caso, o paciente apresentou uma leucometria global extremamente elevada, sendo observada cerca de 570.200 células/ $\mu \mathrm{L}$, devido a intensa linfocitose (553.094 células/ $\mu \mathrm{L}$ ), o que caracteriza estágio avançado da doença.

O mielograma é uma ferramenta diagnóstica essencial. Nesse paciente foi observado um aumento de linfócitos e contagem de linfoblastos superior a $30 \%$ na medula, o que corrobora com os dados descritos na literatura (Adam et al., 2009).

Embora não seja o padrão-ouro, a definição de fenótipo é uma das possíveis aplicabilidades do ensaio de clonalidade, sendo uma técnica útil em situações onde não é possível realizar a imuno-histoquímica (IHQ) da neoplasia (Avery e Avery, 2007). Nesse contexto, Burnett et al. (2003) detectaram correlação entre a imunofenotipagem e a clonalidade em 41 de 42 casos; e Nowosh et al. (2017) concluíram que a PRRA é um método viável por permitir, ainda, realização a partir de esfregaços fixados e corados.

Apesar da viabilidade da PRRA para a determinação do fenótipo, a aplicação da citometria de fluxo para identificação dos marcadores de membrana da população neoplásica seria desejável e permitiria mais informações a respeito da biologia do tumor, mas infelizmente não houve acesso a esta técnica. Apesar

\section{Referências}

ADAM, F.; VILLIERS, S.E.; WATSON, K.; COYNEAND, L.B. Clinical pathological and epidemiological assessment of morphologically and immunologically confirmed canine leukaemia. Veterinary and Comporative Oncology, v.7, n.3, p.181-195, 2009.

AVERY, A.C.; AVERY, P.R. Determining the significance of persistent lymphocytosis. Veterinary Clinics of North America: Small Animal Practice., v.37, n.2, p.267-282, 2007.

BARBOZA, D.V.; GRALA, C.X.; SILVA, E.C.; SALAME, J.P.; BERNARDI, A.; SILVA, C.B.; GUIM, T.N. Estudo retrospectivo de neoplasma em animais de companhia atendidos no hospital de clínicas veterinárias da Universidade Federal de Pelotas durante 2013 a 2017. Pubvet, v.13, n.4, a.312, p.1-12, 2019.

BIENZLE, D. Hematopoietic neoplasia. In: LATIMER, K.S. (ed). Duncan and Prasse's Clinical Pathology. Ames, lowa State University Press Wiley-Blackwell, 2003. p.80-90.

BURNETT, R.C.; VERNAU, W.; MODIANO, J.F.; et al. Diagnosis of Canine Lymphoid Neoplasia Using Clonal Rearrangements of Antigen Receptor Genes. Veterinary Pathology, v.40, p.32-41, 2003.

COUTO, C.G. Clinicopathologic aspects of acute leukemias in the dog. Journal of the American Veterinary Medical Association, v.186, p.681-685, 1985.

DALECK, C.R.; FONSECA, C.S; CANOLA, J.C. Oncologia em cães e gatos. 2 ed. Rio de Janeiro: Roca, 2016, 766p.

HARVEY, J.W.; TERREL, T.G.; HYDE, D.M.; JACKSON, R.I. Well-Differentiated Lymphocytic Leukemia in a Dog: Long-Term Survival Without Therapy. Veternary Pathology, v.18, p.37-47, 1981. de não ser observada diferença significativa em sobrevida de cães com leucemias tipo B ou $T$, a classificação de LLA em imunofenótipos apresenta valor prognóstico quando associada a outros fatores.

Dificilmente remissões clínicas são alcançadas e são geralmente de curta duração. Na maioria dos casos, os animais não respondem bem ao tratamento preconizado. Esse fato pode ser explicado pela intensa infiltração de células neoplásicas malignas em órgãos, ocasionando sua falência, como o fígado, o qual se torna insuficiente e, portanto, dificulta assim o emprego de quimioterapia combinada, além do risco de sepse devido à neutropenia (Nelson e Couto, 2015).

O prognóstico de cães diagnosticados com LLA, geralmente, é desfavorável uma vez que é uma neoplasia altamente proliferativa e de curso rápido (Avery e Avery, 2007). Mesmo com o uso de quimioterapia agressiva e de tratamento de suporte dependendo da condição do animal, o tempo de sobrevida é reduzido, quase que invariavelmente levando o animal a óbito em um período de 1 a 6 meses, mas raramente excede os 3 meses. Animais não tratados geralmente vivem menos de 2 semanas (Nelson e Couto, 2015). O paciente desse relato também veio a óbito após a primeira sessão de quimioterapia, pouco tempo após o diagnóstico.

MATUS, R.E.; LEIFER, C.E.; MACEWEN, E.G. Acute lymphoblastic leukaemia in the dog: a review of 30 cases. J. Am. Vet. Med. Assoc., v.183, p.859-862, 1983.

MOREIRA, L.; KINAPPE, L.; DUHART, D.; MOTTA, A.S. A geriatria canina e o manejo das doenças neoplásicas: Revisão. Pubvet, v.12, n.4, a.79, p.1-7, 2018

NELSON, R.W.; COUTO, C.G. Medicina Interna de Pequenos Animais. 5 ${ }^{a}$ Ed. Rio de Janeiro: Elsevier, 2015. 1512p.

NOWOSH, V; ALENCAR, N.X.; MACIEIRA, D.B. Applicability of PCR-based clonality assay in dogs with multicentric lymphoma. Arquivo Brasileiro de Medicina Veterinária e Zootecnia, v.69, n.3, p.761-765, 2017.

SUTER, S.E.; SMALL, G.W.; SEISER, E.L.; et al. FLT3 mutations in canine acute lymphocytic leukemia. BMC Cancer, v.11, p.38, 2011.

VAIL, D.M. Neoplasia Linfóide. In: BIRCHARD, S.J.; SHERDING, R.G. Manual Saunders. Clínica de Pequenos Animais. $3^{a}$ Ed. São Paulo: Roca, 2008. p.303-305.

VARDIMAN, J.W. The World Health Organization (WHO) classification of tumors of the hematopoietic and lymphoid tissues: an overview with emphasis on the myeloid neoplasms. ChemicoBiological Interaction, v.184, n.1-2, p.16-20, 2010.

WITHROW, S.J.; PAGE, R.; VAIL, D.M. Small Animal Clinical Oncology. E-Book. St. Louis Missouri: Elsevier Health Sciences, 2013, 768p. 